\title{
JOURNALISM GUARDIANS IN A TIME OF GREAT CHANGE: NEWSPAPER EDITORS' PERCEIVED INFLUENCE IN INTEGRATED NEWS ORGANIZATIONS
}

By Peter J. Gade

A national survey of top newspaper editors explored industry uncertainty and organizational change and how organizational integration, team-based newsrooms, newspaper size, and profit emphasis impact editors' perceived organizational influence. Findings indicate that newspaper size and extent of integration predict perceived organizational influence, while profit emphasis is a negative predictor. Editors generally welcome working with non-news departments, and see their influence in their advocacy of journalism values throughout the organization. Editors do not see benefits resulting from newsroom reporting teams.

The traditional mass media model-characterized by relatively few media creating and controlling content disseminated to large, mass audiences-has been replaced in the past decade by a new model that features many media disseminating content to smaller, niche audiences who are active, purposive, and more in control of their media choices. ${ }^{1}$ This evolution has had a profound impact on traditional mass media, which have been forced to change the way they do business and strategically reposition themselves in the rapidly changing media marketplace. ${ }^{2}$

For the newspaper industry, the mandate for change has been apparent for more than a decade. ${ }^{3}$ Concerned by a dwindling base of readers and the impact of the Internet and emergent technologies, the industry has repositioned itself by developing new information and service products in electronic markets and focusing on the interests of potential readers in its print products. ${ }^{4}$ These changes have shifted priorities and resources at the organizational level, as newspapers become more reader-oriented, market-driven, and technologically savvy. Ongoing change efforts since the mid-1990s have seen newspaper organizations become more integrated, as news and business managers and staff collaborate on inter-departmental teams charged with the strategic development of information products. ${ }^{5}$ Newsrooms are also being restructured, and team-based newsrooms, with flatter organizational hierarchies and dif-

Peter J. Gade is an associate professor in the Gaylord College of Journalism and Mass Communication, University of Oklahoma.

JEMC Quarterly

Vol. 85, No. 2

Summer 2008

371-392

(C)2008 AEJMC 
ferent roles for newsroom managers, have replaced or supplemented the beat system, especially at larger newspapers. ${ }^{6}$ As newspapers become more market-driven, traditional definitions of news values have been called into question. ${ }^{7}$ However, despite the uncertainty associated with markets, technology, readership, and news values, profit expectations remain high. ${ }^{8}$

These changes create a different environment for editors as managers, who are required to accept new organizational roles and expectations. Journalism skills and judgment must be supplemented with a greater marketing consciousness and collaboration with non-news departments. ${ }^{9}$ The union of journalism and marketing has not been a harmonious marriage for many editors (and journalists), who see a stronger marketing orientation as a loss of editorial control and an affront to journalistic "professionalism." 10 The "duality" of purpose for news organizations, as journalistic and commercial enterprises, has been shown in numerous studies to create a tension borne from conflicting values. ${ }^{11}$

This duality adds to the complexity of managing change. ${ }^{12}$ Organizational integration has important implications for organizational decision making, including access to resources and how they are used, and for how influential journalism values are to be as newspapers try to respond to industry uncertainty. ${ }^{13}$ To date, there have been no attempts to measure how integration is occurring in newspaper organizations. Top editors (journalists in the highest positions in their organizations' hierarchies) are positioned in news organizations as the primary source of journalism expertise. To the extent that editors perceive they have organizational influence, they should be effective advocates for journalism throughout the organization. ${ }^{14}$

This study, a national survey of top editors, measures editors' attitudes toward concepts drawn from theories of organizational development and organizational support that are important to explaining the ongoing changes in the newspaper industry. It introduces two conceptsorganizational integration and perceived organizational influence-that advance an understanding theoretically and practically of what it means to be the editor of a U.S. newspaper in a time of considerable uncertainty and rapid change.

Literature Review
Newspaper Change: Integration, Teams, Editor Influence, Profit, and Professionalism. The clamor for change increased in the mid-1990s as leading editors asserted the need to "blow up" the newsroom and recreate an organizational culture that was not so adversarial, competitive, and isolated from the business interests of the organization. ${ }^{15}$ Newspapers turned to outside consultants to lead efforts at organizational change; common to these efforts were initiatives to create more reader-driven content, restructure newsrooms into team-based systems of reporting, and integrate organizational decision making by having editors serve on strategic cross-departmental teams. ${ }^{16}$

The restructuring of newspaper organizations has occurred on two levels: the creation of inter-departmental teams that pair news and business personnel in efforts to develop new strategic products or con- 
tent, and the reorganization of newsrooms from a beat system to a team-based system of news coverage. "Organizational integration"the extent of collaboration between historically autonomous units ${ }^{17}$ conceptually describes inter-departmental restructuring and how the collaboration of journalism and business is occurring. Editors appear to recognize the value of working with non-news departments. Sylvie found editors were significantly more likely to say that more cooperation is needed between departments than advertising and circulation department heads. ${ }^{18}$ An Editor $\mathcal{E}$ Publisher study found that $63 \%$ of responding editors agreed there should be more cooperation between news and business/marketing departments. ${ }^{19}$ Campbell, who as editor led broad change initiatives at the Norfolk Virginian-Pilot and St. Louis Post-Dispatch, said that editors should welcome integration as opportunity to "colonize other departments with the values of the newsroom." 20

The reorganization of newsrooms into team-based structures gained momentum throughout the 1990s. A 2000 study found $53 \%$ of newspapers with more than 100,000 circulation used reporting teams, and $37 \%$ of papers surveyed used primarily a team-based system of news coverage. Only $8 \%$ had teams in 1992..1 Team-based systems require journalists to have a broader base of skills; however, this structure should provide flexibility for newspapers to respond more quickly to marketplace opportunities. ${ }^{22}$ Russial found reporting teams produced more content that got more prominent play in the paper than the beat system, and concluded that teams represent an important realignment of newsroom resources. ${ }^{23}$ No studies of editors' perceptions of teambased newsrooms have been done. However, the few studies of journalists working in news teams indicate that journalists perceive less jobrelated authority and less success getting their story ideas in the paper, ${ }^{24}$ and team-based systems require more managers and do not improve the quality of the newspaper. ${ }^{25}$

Changing organizational structures and attempts to be more market-oriented have raised questions about editors' organizational influence. Readers have become the "invisible giants" of the newsroom, with near equal decision-making power as journalists; editors, a trade journal suggested, were losing influence in their newsrooms. ${ }^{26} \mathrm{Harris}$, a journalist and former publisher of the San Jose Mercury News, asserted that the era of editors as "philosopher kings" in the newsroom is over, replaced by editors who are team players with other organizational leaders. Because these leaders have little knowledge of journalism norms and values, "editors need to speak regularly and articulately about the professional and ethical responsibilities of journalism, and also be respectful teachers and patient listeners on these subjects." ${ }^{27}$

Newspapers have historically enjoyed high profits, and despite losses in circulation and advertising revenue, profit levels remain comparable to pharmaceutical and oil industries. ${ }^{28}$ The emphasis on maintaining high profits has been linked to recent waves of cost-cutting, fewer newsroom resources, and greater marketing focus, often at the expense of journalistic performance. Studies have consistently found 
that investments in newsrooms are related to increased circulation and profitability. ${ }^{29}$ However, newsrooms have endured a litany of cost-cutting measures, including staff reductions of about 3,500 journalists since 2000, about $7 \%$ of all newspaper journalists. ${ }^{30}$ Meyer asserted that newspapers have maintained high profits by investing less in their newsrooms, putting out cheaper products, and raising advertising and subscription rates. ${ }^{31}$ Lacy and Blanchard found that higher profits were negatively related to the number of full-time journalism employees, and "the relationship became much stronger for newspapers with profit margins above average." 32 Beam found newsroom managers acknowledge the profitdriven nature of news media, and when they believe profit interferes with the journalistic mission, their job satisfaction suffers. ${ }^{33}$ In earlier research, he concluded that efforts to make newspaper organizations more marketoriented have eroded journalists' capability to maintain control over the values that guide their work, resulting in a "deprofessionalization" of journalism..$^{34}$

Journalism is guided by professional values, including public service, allegiance to truth, journalistic autonomy, and social responsibility. ${ }^{35}$ Newsroom managers report higher levels of professionalism at larger papers, which make fewer errors, do more investigative reporting, and win more professional prizes. ${ }^{36}$ Efforts to change or redefine the values associated with professionalism often face resistance. ${ }^{37}$ Change has been associated with lower morale, ${ }^{38}$ a desire to leave the newspaper industry, ${ }^{39}$ corporate mandates for $\mathbf{2 0 \%}$ profit margins, ${ }^{40}$ and a sense that public service is dying as the sine qua non of journalism. ${ }^{41}$ Several studies found that journalists tend to blame newsroom managers-their editors-for mismanaging change.42 However, some studies also found that editors are conflicted by the motives and values associated with change. ${ }^{43}$

Managing the internal organizational tension that arises from a duality of purpose is a core challenge of newspaper management. ${ }^{44}$ Sylvie and Moon found from three newspaper case studies that management"via sheer will" - pushed through initiatives to change the organizational culture. They concluded that management's approach "does not signify improved management or-in the case of newsrooms-a smooth marriage of journalism and marketing concerns." ${ }^{45}$ Russo found that editors have trouble acknowledging traditional values when organizational priorities are not consistent with professional expectations; newspaper journalists going through organizational change had higher levels of professional identification than organizational identification. She concluded that journalists' professionalism "served as a source of collective inspiration, energy and strength." 46

Organizational Development, Integration, Support, and Influence. To be competitive in changing markets, organizations must be innovative. Larger organizations have more complex and bureaucratic structures that tend to slow their ability to exploit market opportunities. However, they have greater resources, expertise, and market power, thus providing more strategic options for innovation. ${ }^{47}$ Organizational development is the process of organizational change and learning that assumes firms must find ways to adapt and innovate to be competitive. ${ }^{48}$ 
The process of organizational development is not easy because change requires giving up what is known and routine for something new that may not be understood. ${ }^{49}$ Scholars agree that a key to development is organizational integration. Integration breaks down organizational barriers, creating opportunities for exchanges of knowledge throughout the organization. Inter-departmental teams are examples of organizational integration. These teams are expected to contribute to innovation because they create structural mechanisms for fresh thinking. ${ }^{50}$ However, this restructuring requires a different managerial mindset. Managers need to give up their "span of control" and forge a "span of relationships," sharing power and accountability with other departments in the organization. ${ }^{51}$ Managers must act more as "learners than knowers, listeners than tellers, partners than adversaries." 52 This change is not easy for many managers, especially those accustomed to being the primary authorities. ${ }^{53}$

Within these shifting organizational boundaries, managers are expected to be influential because their position in the organizational structure provides opportunities for leadership. ${ }^{54}$ Management, especially during times of change, is expected to articulate a vision of the organization's mission and the values that support it. ${ }^{55}$ Effective managers show organizational leadership, which some scholars have called the "management of meaning." 56 Managers have organizational influence when they are successful at identifying what is important and have the ability to induce others to behave a certain way. ${ }^{57}$ Organizational influence is related to a manager's sense of organizational support. Managers who perceive they are valued by their organizations sense they have greater support to take risks, and greater influence to initiate changes that redefine organizational norms. ${ }^{58}$ Employees recognize managers who have influence in important organizational decisions, and respond by increasing behaviors that benefit the organization. ${ }^{59}$

Newspaper organizations are becoming more integrated, and news managers are increasingly working with non-news departments to strategize, plan, and market. ${ }^{60}$ Managing requires stronger business awareness, increased collaboration, and more subtle leadership skills. Editors are positioned in integrated organizations to be a voice for

Research Questions and Hypotheses journalism professional values throughout the organization; however, change has been associated with transforming the newsroom culture and diminished editorial influence. ${ }^{61}$ Editors' perceived organizational influence begins to explain the extent that editors can be effective advocates for journalism values throughout the organization. Organizational integration and editors' perceptions of their organizational influence have not been studied.

RQ1: To what extent do top newsroom editors perceive their organizations are integrated?

RQ2: How influential do editors perceive they are in 
their organizations? In other words, what is their level of perceived organizational influence?

Newsrooms are being reorganized into team-based structures of news coverage, especially at larger newspapers. ${ }^{62}$ Team-based newsrooms are a tangible change that requires training, re-ordering of work and routines, and a different management approach. ${ }^{63}$ The few studies of newsroom teamwork indicate that journalists have not embraced this structural change, ${ }^{64}$ although no studies exist regarding newsroom managers' attitudes toward team-based newsrooms.

RQ3: What are editors' attitudes toward team-based newsrooms?

Large newspapers exhibit more journalistic professionalism than smaller papers, and to be the editor of a large newspaper reflects a high degree of professional achievement. ${ }^{65}$ Larger organizations are more complex and have greater resources, market leverage, and reservoirs of expertise. ${ }^{66}$ Accordingly, news managers in large organizations are respected professionals who have more strategic tools and options as they consider innovative responses to market uncertainty.

H1: Organizational size is a significant predictor of editors' perceived organizational influence.

Managers in integrated organizations are sources of specialized knowledge, exchanging their expertise across organizational boundaries. ${ }^{67}$ They are expected to be sources of innovation and leadership, ${ }^{68}$ developing spans of influence throughout the organization. ${ }^{69}$ Their sense of organizational influence should be shaped by the extent of their organizational integration.

H2: Organizational integration is a significant predictor of editors' perceived organizational influence.

Newspaper industry emphasis on profit is well-established..$^{70}$ Editors acknowledge newspapers are market-driven, ${ }^{71}$ and staffs are becoming smaller. In an era of market uncertainty and much experimentation with new products and new media, editors have fewer newsroom resources. ${ }^{72}$ Editors react negatively when they perceive profit motive interferes with the journalistic professionalism. ${ }^{73}$

H3: Emphasis on profit is a significant negative predictor of perceived organizational influence. 
Book (2003) listed 1,457 daily newspapers. ${ }^{74}$ This population was divided into four circulation strata for sampling: less than $25,000(1,044$ newspapers), 25,000 to 49,999 (194 newspapers), 50,000 to 99,999 (114 newspapers), and more than 100,000 (105 newspapers). Top editors were defined as having titles of executive editor, editor, managing editor, editor in chief, and vice president for news. Because larger papers often have two newsroom managers with one of these titles, the top two editors at papers with more than 50,000 circulations were included when there were two people with one of these titles.

A census of top editors at papers larger than 25,000 was included in the sample. This meant that the initial sample included 194 editors in the 25,000 to 49,999 range, 200 editors in the 50,000 to 99,999 range, and 197 editors from papers with more than 100,000 circulation. Because there were about 200 editors in each of these strata, a similar-sized random sample (one-fifth) was drawn from the 1,044 papers with circulations less than 25,000 $(n=208)$. The initial mailing list included 799 editors.

The survey was sent postal mail in June 2004. A pre-notification email was sent to potential respondents to increase the response. ${ }^{75}$ Subsequently, 36 editors were removed from the sample because they had left their jobs and their replacement could not be identified by searching the papers' Web sites. ${ }^{76}$ This left a sample of 763 editors. Dillman's tailored design method for postal surveys was followed closely."

Variable Measures. Respondents expressed agreement or disagreement with statements on a five-point Likert-like intensity scale. Organizational integration explores the extent to which organizational boundaries are changing, and how the integration of journalism and business is occurring (eight statements, Cronbach's alpha $=.70$ ). Perceived organizational influence measures the extent to which editors think they are influential and journalism values are important in their organizations (seven statements, alpha $=.73$ ). Team-based newsrooms measures editor attitudes toward news coverage teams in terms of newsroom efficiency and journalism quality (two statements, alpha $=.87$ )..$^{78}$ Profit measures editors' perceptions of organizational emphasis and their personal attention to profit (two statements, Cronbach's alpha $=.55$ ). ${ }^{79}$ Organizational size is measured by newspaper circulation. Demographic data were also sought.

Responses were coded so a positive response indicated support for the concept (e.g., positive responses indicated high organizational integration, high perceived organizational influence, high profit emphasis). Construct quotients (the mean response to the set of statements measuring the concept) measure respondents' attitudes toward the concepts. To determine whether the quotient and statement means are significantly different from the neutral point ( 3.0 on a five-point scale), the standard error of the mean was used to calculate confidence intervals for each measure. Response means more than $+/-2$ standard errors from the neutral point are significant at the $95 \%$ confidence level. ${ }^{80}$ Accordingly, means significantly above 3.0 indicate positive agreement with a concept, and means significantly below 3.0 indicate disagreement. 


\section{TABLE 1}

\section{Organizational Integration (Eight Statements; Cronbach's Alpha $=.70$ )}

Items were arrayed on a five-point scale, ranging from (1) strongly disagree to (5) strongly agree. Means more than $+/-2$ standard errors from the neutral point (3.0) are significant at the $95 \%$ confidence level.

Construct

Organizational Integration

Statements

The news and business interests of this newspaper are essentially the same.

As editor, it is important for me to communicate the values of the rest of the organization to the newsroom.

As editor, I am focused on work-related roles outside the newsroom as much as I am focused on the day-to-day content of the newspaper.

I am as confident in my abilities as a news manager in a business sense as I am in my abilities as a news editor in a journalistic sense.

The newsroom must be supportive of our company's attempts to aggressively pursue emerging business opportunities.

Cross-departmental teams, which partner people from various departments, have improved our organizational decision making.

As editor, I am an organizational team player, working with other departments to guide the organization's operations.

I am committed to changes that increase collaboration between the news and business interests of the organization.
Mean Std. Dev. SE N

$3.63^{\star \star} \quad .56 \quad .03 \quad 263$

$\begin{array}{llll}2.77^{\star \star} & 1.04 & .06 & 272\end{array}$

$\begin{array}{llll}4.43^{\star *} & .72 & .04 & 273\end{array}$

$\begin{array}{llll}3.14^{*} & 1.16 & .07 & 271\end{array}$

$\begin{array}{llll}3.89^{* *} & .94 & .06 & 272\end{array}$

$3.74^{\star *} \quad .95 \quad .06 \quad 272$

$\begin{array}{llll}3.53^{\star *} & 1.03 & .06 & 270\end{array}$

$\begin{array}{llll}4.16^{* \star} & .76 & .05 & 270\end{array}$

$\begin{array}{llll}3.28^{\star \star} & 1.08 & .07 & 269\end{array}$

${ }^{\star} p<.05 ;{ }^{* *} p<.01$

Results

Of the 763 editors surveyed, 274 completed surveys were returned, a response rate of $35.9 \%$. Respondents managed 243 newspapers in 46 states and included top editors from 142 of the 219 U.S. newspapers with circulations above $50,000 .^{81}$ About three-fourths of responding editors were men, $87 \%$ were white, their average age was 50 , and they had been the top editor for about six years. ${ }^{82}$

The first research question asked to what extent do top editors perceive their organizations are integrated. The quotient mean is 3.63 , which is significantly higher than the neutral point $(\mathrm{SE}=.03, p<.001)$, indicat- 
ing that top editors show significant agreement that their organizations are integrated (see Table 1). Assessing the individual statements, all eight statements are significant, with seven indicating positive attitudes toward organizational integration.

Editors show strongest agreement (means noted parenthetically) that it is important for them to communicate the values of the rest of the organization to the newsroom (4.43), and their jobs as editors make them organizational team players who work with other departments to guide operations (4.16). Editors strongly agree that they are as confident in their management abilities in a business sense as they are in their abilities in a journalistic sense (3.89). Editors also agree that the newsroom must be supportive of the company's attempts to aggressively pursue emerging business opportunities (3.74), and that cross-departmental teams (pairing news and non-news personnel) have improved organizational decision making (3.53). Editors are committed to changes that increase collaboration between news and business interests (3.28). However, they show mild, but significant, disagreement that the news and business interests of their newspapers are essentially the same (2.77). Together, the responses reveal that editors are active managers in integrated organizations. They are confident working outside the newsroom and they value their work with non-news departments. Editors perceive their role is to advance a stronger business consciousness in the newsroom; however, they recognize a tension between news and business, although this tension is not strong for many editors.

RQ2 explored the level of the editors' perceived organizational influence. The construct quotient (3.56) is significantly different from the neutral point ( $\mathrm{SE}=.04, p<.001)$, showing editors agree they have a relatively high level of perceived organizational influence (see Table 2). Six of the seven statements have significant levels of agreement or disagreement. The editors showed strongest agreement that exhibiting an open passion for traditional journalism values is an effective method to gain influence in their organizations (4.19), and that their ideas regarding the newsroom and newspaper are valued throughout the organization (4.14). They disagree strongly that they are losing influence in their newsrooms (2.28). They also disagree that business interests think they should have a say in deciding how the newsroom operates (2.34), and that the journalistic interests of the newsroom are becoming less central to the mission of the news organization (2.51). Despite this optimism, editors indicate they recognize limits of their influence, responding that the decisive power in newspaper organizations is exercised by capital investors more than newsroom managers (3.09). Taken together, editors perceive they have moderately strong influence in their organizations and newsrooms, and they associate their influence with advocacy of journalism values. They appear optimistic about their personal influence in managing the tension that arises between journalistic and business interests in the organization, but they also perceive that their ultimate influence might not be as powerful as investors from outside the organization. 


\section{TABLE 2}

Perceived Organizational Influence (Seven Statements, Cronbach's Alpha $=.73$ )

Items were arrayed on a five-point scale, ranging from (1) strongly disagree to (5) strongly agree. Means more than $+/-2$ standard errors from the neutral point (3.0) are significant at the $95 \%$ confidence level.

Construct

Perceived Organizational Influence

\section{Mean}

$3.56^{* *}$

Statements

My ideas regarding the newsroom and newspaper are valued throughout this organization.

\#Business interests in this organization think they should have a hand in deciding how the newsroom operates.

\# The decisive power in newspaper corporations today is exercised by capital investors more than newsroom managers.

Exhibiting an open passion for traditional journalism values (e.g., independence, truth, and watchdog reporting) is an effective method for today's editors to gain influence in their organizations.

\# As newspapers become more focused on audiences, editors are losing influence in their newsrooms.

\#The journalistic interests of the newsroom are becoming less central to the mission of this organization.

\# The opportunity for an independent-minded editor to run her or his own newsroom has ended.

$2.34^{\star \star}$

3.09

$4.19^{\star \star}$

$4.14^{\star \star} \quad .85 \quad .05$

273

1.21

.07

272

1.21

.07

271

.89

.05

271

$N$

264 


\section{TABLE 3}

Perceived Organizational Influence Regressed on Demographic Variables, Team-based Newsrooms, Organizational Size, Organizational Integration, and Profit

Variable

Standardized Beta

Coefficients

Career Experience

Time Current Position

$-.051$

Age

$-.008$

Gender

$-.011$

Ethnicity

$-.011$

( $R^{2}$ for block)

.002

Team-based Newsrooms

$-.063$

( $R^{2}$ change)

.000

Organizational Size

$.219^{* *}$

( $R^{2}$ change)

.064

Organizational Integration $\quad .230^{\star \star}$

( $R^{2}$ change)

.049

Profit

$-.441^{\star *}$

( $R^{2}$ change)

.194

Cumulative $\mathrm{R}^{2}$

.330

Cumulative Adjusted $R^{2}$

.303

${ }^{* *} p<.001$

To test the hypotheses, perceived organizational influence was regressed on the predictor variables-organization size, organizational integration, and profit, controlling for the impact of demographics and attitudes toward team-based newsroom structures. The model predicted about $30 \%$ of the variance (adjusted $\mathrm{R}^{2}=.303$ ); none of the control variables was significant.

H1 anticipated that organizational size would predict perceived organizational influence. H1 was supported, as organizational size was a significant predictor (beta $=.219$ ) that explained $6.4 \%$ of the variance (see Table 3). The data indicate that as organizational size increases, editors perceive themselves as more influential in their organizations; they are managers who think their views are more respected and valued throughout the organization, including among business interests outside the newsroom. As such, editors at larger papers perceive themselves to be in a more effective position to advocate journalism professionalism, they have greater resources at their disposal to meet the challenges of uncertainty and change, and they have more success buffering the newsroom from market influences that conflict with journalism values. 
H2, which proposed that organizational integration would predict editors' perceptions of their organizational influence, was supported (beta $=.230$ ), explaining about $5 \%$ percent of the variance in the model. This result supports the idea that editors see the importance of their roles outside the newsroom and think their organizational influence is enhanced by these expanded roles. Editors understand that their integration and collaboration with non-journalistic interests in the organization provides them opportunities to be influential beyond the newsroom and throughout the organization, forging spans of influence as part of the organization's management team. This finding speaks to the extent that the organizational culture of newsrooms has changed in the past decade, and editors perceive the "wall" that separated the newsroom from the business interests of the organization is no longer an effective organizational boundary. Editors see themselves as key leaders in this cultural transition. They acknowledge that journalism and business interests differ, yet accept that competing values must co-exist. Their influence as editors is based in part on their ability to advocate journalism interests throughout the organization while pushing the newsroom to accept a more marketoriented culture.

H3 predicted that an organizational emphasis on profit would have a negative impact on editors' perceptions of their organizational influence. This hypothesis was supported, as profit was the strongest predictor in the model (beta $=-.441$ ), explaining more than $19 \%$ of the variance. This finding shows that editors think an emphasis on profit, relative to the other variables, is a powerful restraint on their organizational influence. They think their organizations favor profit over non-profit goals. Accordingly, although the editors see themselves as leaders and sources of innovation, their ability to respond to industry uncertainty is hampered by an emphasis on profit, a shrinking pool of resources, and smaller newsroom budgets. The data support the idea that editors perceive that profit emphasis reduces their organizational influence outside and inside the newsroom: as ambassadors throughout the organization, arguing, first, that quality journalism is good business and, second, that business interests must be better accepted and understood within the newsroom.

This study sought to better understand what it means to be the editor of a U.S. newspaper at a time the industry is in a period of fundamental organizational change. Newspapers have found their business model is antiquated and seek innovative answers to maintain readers and attract new customers. Editors, as the organization's top newsroom managers and journalism professionals, are a key source of organizational knowledge and competency, and accordingly should be important organizational leaders in crafting responses and a vision to meet the challenges facing the industry. Yet all agents work within an organization's structure, ${ }^{83}$ and the integration of newspaper organizations-the strategic synthesis of the news and business interests-raises some doubt about the values that will continue to guide newspaper organizations and the importance of traditional journalism values. 
The responding editors perceive themselves as important managers throughout the organization, not just in the newsroom. They are confident of their ability, and they value their roles outside the newsroom. They acknowledge increased collaboration between the newsroom and non-news departments and are generally comfortable in these roles. They see themselves as a bridge between the newsroom and non-news departments, and one of their roles is communicating the values of the rest of the organization to the newsroom.

The editors report moderately strong perceived organizational influence, and a basis for this influence is their advocacy of journalism values throughout their organizations. The predictors of perceived organizational influence-organizational size, organizational integration, and profit-illustrate both the scope and limits of editors' influence. Editors at larger newspapers are more likely to manage news organizations that are respected for their journalism professionalism. ${ }^{84}$ Larger papers have greater resources to pursue journalistic goals (e.g., enterprise and watchdog reporting), and are more likely to win prestigious journalistic awards. Accordingly, the papers are important arbiters of social and political influence in largely urban and regional settings. The top editors of these large, complex organizations have generally reached a level of professional accomplishment that surpasses their peers at smaller papers. This begins to explain why these editors perceive greater organizational influence than their colleagues.

Organizational integration suggests that editors who work with other departments-striving to create spans of relationships, as opposed to intra-departmental spans of control-perceive greater organizational influence. This finding should bode well for editors who are striving to advance the journalistic interests of their papers throughout their organizations. However, it is important to note that organizational integration creates structural opportunities for influence to flow in multiple directions. The integration of journalism and business raises the dual questions of the impact of business interests on the editors' journalism values and whether the editors' advocacy of journalism values is diminished or diluted in the exchange of ideas. In a related way, the data suggest a somewhat inconsistent optimism: editors think they can be influential voices for journalism throughout their organizations, while being effective at limiting the influence of business interests inside the newsroom.

Profit was the strongest predictor of perceived organizational influence; editors who think their organizations place more emphasis on profit have lower levels of perceived organizational influence. Editors appear to accept profit emphasis as an expectation they cannot manage (it is beyond their control), but they acknowledge that profit expectations impact their ability to influence people and affect change. This suggests that editors facing higher profit pressures are less influential advocates of journalism values, and they recognize that emphasis on profit cuts into their resources for creating stronger products and better employees. They see that external forces - their corporations and investors-are pushing them in uncomfortable directions. 
The benefits of team-based newsrooms are not readily apparent to most editors in this study. Editors don't see teams as a better use of their resources, nor do they think the team system produces better quality journalism. These results hold for editors at all size newspapers..$^{85}$ Although surprising given editors' embrace of organizational integration and crossdepartmental teams, this finding fits well with the small body of research that indicates rank-and-file journalists have not embraced team-based newsrooms. ${ }^{86}$ Team-based systems require training and new, broader skill sets. Reporting teams require more staff coordination and planning, which reduces time spent on information gathering, writing, and editing. These are tangible changes that editors don't see as an efficient use of limited resources or as resulting in better journalism.

Change is a process, and survey research is limited to capturing a snapshot of respondents' attitudes at one point in time. Since this study was conducted, the newspaper industry has endured noteworthy changes that are not reflected in these data. ${ }^{87}$ Also, asking editors about perceptions of their influence carries a risk that they might inflate their value through self-reports. However, perception is an important concept in management and organizational literature; organizational members' attitudes and actions are shaped by their perceptions. ${ }^{88}$ In this study, editors appear to be quite candid, acknowledging the limits of their influence. Future research could ask other organizational members-both in and out of the newsroom-about sources of organizational influence and news managers' effectiveness as organizational advocates for journalism and as advocates for non-news interests in the newsroom.

The study of organizational integration strives to understand how the boundaries and structures of organizations are shifting. Organizational development and the innovation that integration is expected to nurture often occurs along these shifting boundaries, where ideas and their advocates compete for organizational influence. ${ }^{89}$ Editors realize that their newsrooms can no longer be isolated from the interests of other departments in the organization. But, most important, this study illustrates the unique position editors hold in integrated news organizations -that of primary advocate for journalism values. Editors recognize that they must get out of the newsroom and engage other departments in the news organization. In this sense, they are organizational bridges and buffers, attempting to advance journalism professionalism throughout the organization while protecting the newsroom from marketing schemes at odds with journalism. These roles appear increasingly important to preserving journalism values in the twenty-first century, as newspaper organizations, facing ongoing threats to their core business, will continue to experiment with new products, technologies, and business partners to reach out to audiences in ways that often appear at odds with journalistic principles.

\section{NOTES}

1. Steven H. Chaffee and Miriam J. Metzger, "The End of Mass Communication?" Mass Communication \& Society 4 (fall 2001): 365-79; 
John W. Dimmick, Media Competition and Coexistence: The Theory of the Niche (Mahwah, NJ: Lawrence Erlbaum, 2003), 23-42.

2. Sylvia M. Chan-Olmsted, Competitive Strategy for Media Firms: Strategic and Brand Management in Changing Media Markets (Mahwah, NJ: Lawrence Erlbaum, 2006), 4-10.

3. Tim McGuire, "Sharing the Excitement of Newspaper Change," ASNE Bulletin (October 1994): 5; Peter J. Gade, "Newspapers and Organizational Development: Management and Journalist Perceptions of Newsroom Cultural Change," Journalism \& Communication Monographs 6 (spring 2004).

4. Project for Excellence in Journalism, "State of the News Media 2006," accessed March 24, 2006 at <http: / / www.stateofthenewsmedia. com/2006/narrative_newspapers_intro.asp?cat=1\&media=3>; Robert G. Picard, "Strategic Responses to Free Distribution Daily Newspapers," International Journal of Media Management 2 (autumn 2001): 167-72.

5. George Sylvie and Patricia D. Witherspoon, Time, Change and the American Newspaper (Mahwah, NJ: Erlbaum, 2002), 51-55; Alicia Shepard, "Blowing Up the Wall," American Journalism Review (December 1997): 18-27; Charles Rappleye, "Cracking the Church-State Wall," Columbia Journalism Review (January/February 1998): 20-23; Joe Strupp, "Where There's a Wall There's a Way," Editor \& Publisher $132(50,1999)$ : 20-23.

6. Ann B. Schierhorn, Fred Endres, and Carl Schierhorn, "Newsroom Teams Enjoy Rapid Growth in the 1990s," Newspaper Research Journal 22 (summer 2001): 2-15; Alicia Shepard, "The Change Agents," American Journalism Review (May 1998): 42-49.

7. Robert G. Picard and Jeffrey H. Brody, The Newspaper Publishing Industry (Boston: Allyn \& Bacon, 1997), 129; Carl Sessions Stepp, "Reader Friendly: Their Futures Uncertain, Newspapers are Undergoing a Profound Change in the Way They Carry Out Their Missions," American Journalism Review (July/August 2000): 22-43; Randal A. Beam, "How Perceived Environmental Uncertainty Influences the Marketing Orientation of U.S. Daily Newspapers," Journalism \& Mass Communication Quarterly 73 (summer 1996): 285-303.

8. Philip Meyer, The Vanishing Newspaper: Saving Journalism in the Information Age (Columbia, MO: University of Missouri Press, 2004). Meyer argues that the emphasis on maintaining high profits has resulted in newspapers investing less in their newsrooms, putting out cheaper products, and raising advertising and subscription rates. He credits Harvard professor Michael Porter for describing this strategy as "harvesting market position" (8-10). Also see chapter 2, "How Newspapers Make Money," 34-46.

9. Jay Harris, "What Business Are We In?" The American Editor (April 2004): 5-8; Don Campbell, "Help Wanted: Newspapers Are Finding It Increasingly Difficult to Fill Top-Level Editing Positions," American Journalism Review (November 2002): 56-61; Stepp, "Reader Friendly."

10. Randal A. Beam, "Organizational Goals and Priorities and the Job Satisfaction of U.S. Journalists," Journalism \& Mass Communication 
Quarterly 83 (spring 2006): 169-85; Beam, “How Perceived Environmental Uncertainty Influences the Marketing Orientation of U.S. Daily Newspapers," 285; Gade, "Newspapers and Organizational Development," 4142; Peter Gade, "Managing Change: Editors' Attitudes Toward Integrating Marketing and Journalism," Newspaper Research Journal 23 (spring/summer 2002): 148-53; Doug Underwood, When MBAs Rule the Newsroom (New York: Columbia University Press, 1993).

11. Leona Achtenhagen and Elena Raviola, "Organizing Internal Tension: Duality Management of Media Companies" in Organizing Media: Mastering the Challenges of Organizational Change, ed. Leona Achtenhagen (Jönköping, Sweden: Jönköping International Business School, 2007), 12745; David H. Weaver, Randal A. Beam, Bonnie L. Brownlee, Paul S. Voakes, and G. Cleveland Wilhoit, The American Journalist in the 21st Century (Mahwah, NJ: Lawrence Erlbaum, 2007), 234-36; Gade, "Newspapers and Organizational Development," 44-45. For a discussion of how market-driven changes in newspapers and news media conflict with journalism values, see Underwood, When MBAs Rule the Newsroom, and John H. McManus, Market-Driven Journalism: Let the Citizen Beware (Thousand Oaks, CA: Sage, 1994).

12. Achtenhagen and Raviola, "Organizing Internal Tension," 130; George Sylvie and Soo Jung Moon, "Framing Change: Who's in Charge in the Newsroom?" in Organizing Media: Mastering the Challenges of Organizational Change, ed. Leona Achtenhagen (Jönköping, Sweden: Jönköping International Business School, 2007), 89-124.

13. Sumantra Ghosal and Lynda Gratton, "Integrating the Enterprise," MIT Sloan Management Review (fall 2002): 31-38; Bart Nooteboom, Learning and Innovation in Organizations and Economies (New York: Oxford University Press, 2000), see chap. 11, "Integration and Disintegration," 209-27; Achtenhagen and Raviola, "Organizing Internal Tension," 127; for a discussion of the integration of marketing-orientation into the decision making of newspaper organizations, see Beam, "How Perceived Environmental Uncertainty Influences the Marketing Orientation of U.S. Daily Newspapers," 285-89.

14. Monty L. Lynn, "Organizational Buffering: Managing Boundaries and Cores," Organization Studies 26 (1, 2005): 37-61; Justin Aselage and Robert Eisenberger, "Perceived Organizational Support and Social Contracts: A Theoretical Integration," Journal of Organizational Behavior 24 (5, 2003): 491-509.

15. Carl Session Stepp, "Reinventing the Newsroom," American Journalism Review (October 1995): 29-33; C. Haswell, "Editors Wrestle with Change," The American Editor (December 1995): 10-11; Chris Peck, "Finding Our Way Means Revising Our Values," in American Society of Newspaper Editors, ASNE Journalism Values Handbook (Reston, VA: American Society of Newspaper Editors, 1996); Cole C. Campbell, "Journalism as a Democratic Art," in The Idea of Public Journalism, ed. Ted Glasser (New York: Guilford Press, 1999), xix.

16. Shepard, "The Change Agents"; Joseph S. Coyle, "Now, The Editor as Marketer," Columbia Journalism Review (July/August 1998): 37-41.

17. Nooteboom, Learning and Innovation in Organizations and Economies, 
209.

18. George Sylvie, "Departmental Influences on Interdepartmental Cooperation at Daily Newspapers," Journalism \& Mass Communication Quarterly 73 (spring 1996): 230-41. 22.

19. Joe Strupp, "Cracks in 'The Wall'?" Editor \& Publisher 132 (49, 1999):

20. Cole C. Campbell, "Cultural Transformation," (seminar on newspaper change at the University of Missouri School of Journalism, Columbia, MO, 21 January 1998).

21. Schierhorn, Endres, and Schierhorn, "Newsroom Teams Enjoy Rapid Growth in the 1990s," 6, 12.

22. Regina L. Lewis, "How the Managerial Evolution Affects Newspaper Firms," Newspaper Research Journal 18 (winter/spring 1997): 103-04, 120.

23. John T. Russial, "Topic Team Performance: A Content Study," Newspaper Research Journal 18 (winter/spring 1997): 142.

24. Mark Neuzil, Kathleen Hansen, and Jean Ward, "Twin Cities Journalists' Assessment of Topic Teams," Newspaper Research Journal 20 (winter 1999): 12-14.

25. Gade, "Newspapers and Organizational Development," 35, 49.

26. Stepp, "Reader Friendly," 24.

27. Harris, "What Business Are We In?" 7.

28. Newspapers have had $2 \%$ to $3 \%$ annual circulation losses since 2004. Profit margins have declined for public newspaper companies in recent years: $21 \%$ in $2004,20 \%$ in $2005,17 \%$ in 2006 , to an estimated "midteens" in 2007. Project for Excellence in Journalism, "State of the News Media 2008," accessed April 3, 2008, at http://www.stateofthenews media.com $/ 2008 /$ narrative_newspapers_economics.php?cat=3\&media =4; Project for Excellence in Journalism, "State of the News Media 2007," accessed February 13, 2008, at http:/ / www.stateofthenewsmedia.com/ 2007 / narrative_newspapers_economics.asp?cat $=3 \&$ media $=3$; Project for Excellence in Journalism, "State of the News Media 2006"; John Morton, "Woe Is the Industry?" American Journalism Review (October/ November 2004): 108.

29. Murali K. Mantrala, Prasad A. Naik, Shrihari Sridhar, and Esther Thorson, "Uphill or Downhill? Locating the Firm on a Profit Function," Journal of Marketing 71 (April 2007): 26-44; Sooyoung Cho, Esther Thorson, and Stephen Lacy, "Increased Circulation Follows Investments in Newsroom," Newspaper Research Journal 25 (fall 2004): 26-39; Steve Lacy and Fred Fico, "The Link Between Newspaper Content Quality and Circulation," Newspaper Research Journal 12 (spring 1991): 46-57; KoangHyub Kim and Philip Meyer, "Survey Yields Five Factors of Newspaper Quality," Newspaper Research Journal 26 (winter 2005): 6-15.

30. Project for Excellence in Journalism, "State of the News Media 2006."

31. Meyer, The Vanishing Newspaper, see chapter 2, "How Newspapers Make Money," 34-46.

32. Stephen Lacy and Alan Blanchard, "The Impact of Public Ownership, Profits, and Competition on Number of Newsroom Employees 
and Starting Salaries in Mid-Sized Daily Newspapers," Journalism \& Mass Communication Quarterly 80 (winter 2003): 961.

33. Beam, "Organizational Goals and Priorities and the Job Satisfaction of U.S. Journalists," 181.

34. Beam, "How Perceived Environmental Uncertainty Influences the Marketing Orientation of U.S. Daily Newspapers," 287.

35. Weaver et al., The American Journalist in the 21st Century, 130-32; David H. Weaver and G. Cleveland Wilhoit, The American Journalist in the 1990s: U.S. News People at the End of an Era (Mahwah, NJ: Erlbaum, 1996), 127; Pamela J. Shoemaker and Stephen D. Reese, Mediating the Message: Theories of Influences on Mass Media Content (White Plains, NY: Longman, 1996), 91-103; John C. Merrill, The Dialectic in Journalism: Toward a Responsible Use of Press Freedom (Baton Rouge, LA: Louisiana University Press, 1989); Tracy Callaway Russo, "Organizational and Professional Identification: A Case of Newspaper Journalists," Management Communication Quarterly 12 (August 1998): 72-111.

36. Randal A. Beam, "The Impact of Group Ownership Variables on Organizational Professionalism at Daily Newspapers," Journalism Quarterly 70 (winter 1993): 907-18. This survey of newspaper editors found that paper size was related to higher scores of journalism professionalism on seven of eight measures.

37. Sylvie and Witherspoon, Time, Change, and the American Newspaper, 61-62; Gade, "Newspaper and Organizational Development," 42; Beam, "How Perceived Environmental Uncertainty Influences the Marketing Orientation of U.S. Daily Newspapers," 285-87; for a broader discussion of how occupational groups attempt to maintain control of their values and organizational cultures, see John Van Maanen and Stephen R. Barley, "Occupational Communities: Culture and Control in Organizations," in Research in Organizational Behavior, ed. Barry M. Staw and L.L. Cummings (Greenwich, CT: Jai Press, 1984): 287-365.

38. Peter J. Gade and Earnest L. Perry, "Changing the Newsroom Culture: A Four-Year Case Study of Organizational Development at the St. Louis Post-Dispatch," Journalism \& Mass Communication Quarterly 80 (summer 2003): 327-47; Gade, "Newspapers and Organizational Development," 33-37; Neil Hickey, "Low - and Getting Lower," Columbia Journalism Review (September/October 2001): 37-39; Doug Underwood, "It's Not Just L.A.," Columbia Journalism Review (January/February 1998): 24-26.

39. Brent Cunningham, "The Art of Managing Morale," Columbia Journalism Review (September/October 2001): 34-36.

40. Neil Hickey, "Money Lust: How Pressure for Profit Is Perverting Journalism," Columbia Journalism Review (July/August 1998): 28-36; John Morton, "Who Will Be Next?" American Journalism Review (April 2000): 72; Morton, "Woe Is the Industry?" 108.

41. Randal A. Beam, "Content Differences between Daily Newspapers with Strong and Weak Market Orientations," Journalism \& Mass Communication Quarterly 80 (summer 2003): 371-72; Meyer, The Vanishing Newspaper, see chapter 10, "How Newspapers Were Captured by Wall Street." Also see Underwood, When MBAs Rule the Newsroom, and 
McManus, Market-Driven Journalism: Let the Citizen Beware.

42. Gade and Perry, "Changing the Newsroom Culture," 331-340; Gade, "Newspapers and Organizational Development," 28-32; Hickey, "Low - and Getting Lower," 37-39.

43. Gade, "Managing Change," 150-152.

44. Achtenhagen and Raviola, "Organizing Internal Tension," 130.

45. Sylvie and Moon, "Framing Change," 115.

46. Russo, "Organizational and Professional Identification," 101.

47. Chan-Olmsted, Competitive Strategy for Media Firms, 8-9; Sylvia Chan-Olmsted, "Issues in Media Management and Technology," in Handbook of Media Management and Economics, ed. Alan B. Albarran, Sylvia Chan-Olmsted, and Michael O. Wirth (Mahwah, NJ: Lawrence Erlbaum, 2006), 255-263.

48. Rosabeth Moss Kanter, The Change Masters: Innovation for Productivity in the American Corporation (New York: Simon \& Schuster, 1983). This book is considered a seminal work in organizational development. For an overview of how change works, see chapter 10, "The Architecture of Culture and Strategy Change," 278-306. Also see Nooteboom, Learning and Innovation in Organizations and Economies, 269-282; William Bergquist, The Postmodern Organization: Mastering the Art of Irreversible Change (San Francisco, CA: Jossey-Bass, 1993), 3-14.

49. Peter DeJager, "Resistance to Change: A New View of an Old Problem," Futurist 35 (May/June 2001): 24-27.

50. Kanter, The Change Masters, 27-36; Rosabeth Moss Kanter, "News Innovation and Leadership," Nieman Reports 56 (summer 2002): 30-34; Nooteboom, Learning and Innovation in Organizations and Economies, 35-51; George P. Huber, The Necessary Nature of Future Firms: Attributes of Survivors in a Changing World (Thousand Oaks, CA: Sage Publications, 2004), 165-72; Deborah Dougherty, "Organizing for Innovation," in Handbook of Organization Studies, ed. Stewart R. Clegg, Cynthia Hardy, and Walter R. Nord (Thousand Oaks, CA: Sage, 1996), 424-39.

51. James R. Fisher, "Envisioning a Culture of Contribution," Journal of Organizational Excellence (winter 2000): 47-54.

52. Fisher, "Envisioning a Culture of Contribution," 50.

53. Douglas Ceasar and William L. Gardner, "Transition to Self-Directed Work Teams: Implications of Transition Time and Self-Monitoring for Managers' Use of Influence Tactics," Journal of Organizational Behavior 25 (February 2004): 47-63.

54. Alan Bryman, "Leadership in Organizations," in Handbook of Organization Studies, ed. Stewart R. Clegg, Cynthia Hardy, and Walter R. Nord (Thousand Oaks, CA: Sage, 1996), 276-92; Chris Argyris, Knowvledge for Action: A Guide to Overcoming Barriers to Organizational Change (San Francisco: Jossey-Bass, 1993), xxi, 2, 49-55. Argyris writes that organizational learning is stymied by organizational cultures, which are rooted in organizational politics. For change to occur, the top levels of management must initiate changes in organizational politics; Edgar H. Schein, Organizational Culture and Leadership (San Francisco: Jossey-Bass, 1985), 2. Schein calls leadership and organizational culture "two sides of the same coin," and writes "the only thing of real importance that leaders do is to 
create and manage culture."

55. Michael W. Grojean, Christian J. Resick, Marcus W. Dickson, and D. Brent Smith, "Leaders, Values, and Organizational Climate: Examining Leadership Strategies for Establishing an Organizational Climate Regarding Ethics," Journal of Business Ethics 55 (December 2004): 223-41.

56. Linda Smircich and Gareth Morgan, "Leadership: The Management of Meaning," Journal of Applied Behavioral Science 18 (September 1982): 257-73.

57. Bryman, "Leadership in Organizations," 276-77; Schein, Organizational Culture and Leadership, 311-27.

58. Aselage and Eisenberger, "Perceived Organizational Support and Social Contracts," 494, 500.

59. Robert Eisenberger, Florence Stinglhammer, Christian Vandenberghe, Ivan Sucharski, and Linda Rhodes, "Perceived Supervisor Support: Contributions to Perceived Organizational Support and Employee Retention," Journal of Applied Psychology 87 (June 2002): 565-73.

60. Sylvie and Witherspoon, Time, Change and the American Newspaper, 9-11; Kanter, "News Innovation and Leadership," 31-33. 24.

61. Harris, "What Business Are We In?" 7; Stepp, "Reader Friendly,"

62. Schierhorn, Endres, and Schierhorn, "Newsroom Teams Enjoy Rapid Growth in the 1990s," 11-13. 63.

63. Ceasar and Gardner, "Transition to Self-Directed Work Teams," 47-

64. Neuzil, Hansen, and Ward, "Twin Cities Journalists' Assessment of Topic Teams," 12-14; Gade and Perry, "Changing the Newsroom Culture," 332; Gade, "Newspapers and Organizational Development," $42-43,49$.

65. Beam, "The Impact of Group Ownership Variables on Organizational Professionalism," 913-14.

66. Chan-Olmsted, Competitive Strategy for Media Firms, 8-9; ChanOlmsted, "Issues in Media Management and Technology," 255-59; David Demers, The Menace of the Corporate Newspaper: Fact or Fiction? (Ames, IA: Iowa State University Press), 129-49.

67. Nooteboom, Learning and Innovation in Organizations and Economies, 35-51; Huber, The Necessary Nature of Future Firms, 143-214.

68. Bryman, "Leadership in Organizations," in 276-77; Argyris, Knowledge for Action, 2, 49-55; Schein, Organizational Culture and Leadership, 2.

69. Fisher, "Envisioning a Culture of Contribution," 50.

70. Meyer, The Vanishing Newspaper, 8-10, 34-46; Hugh J. Martin, "Measuring Newspaper Profits: Developing a Standard of Comparison," Journalism \& Mass Communication Quarterly 75 (autumn 1998): 500-17; William Blankenburg, "Newspaper Scale and Newspaper Expenditures," Newspaper Research Journal 10 (spring 1989): 97-103; Hickey, "Money Lust," 28-36.

71. Gade, "Managing Change," 150-52; Beam, "How Perceived Environmental Uncertainty Influences the Market Orientation of U.S. Daily Newspapers," 294-99. 
72. Project for Excellence in Journalism, "State of the News Media 2007."

73. Beam, "Organizational Goals and Priorities and the Job Satisfaction of U.S. Journalists," 178.

74. Editor \& Publisher International Year Book (New York: Editor \& Publisher Co,, 2003).

75. Herbert Weisberg, Jon A. Krosnick, and Bruce D. Bowen, An Introduction to Survey Research, Polling and Data Analysis (Thousand Oaks, CA: Sage Publications, 1996), 120. The authors note that survey response rates are increased by an average of $8 \%$ when potential respondents are notified shortly in advance of receiving a survey.

76. About 100 pre-notification e-mails were returned because no person existed at the address or the newspapers' e-mail addresses had been changed. The researcher then searched these newspaper Web sites for the names of the editors. If the names could be found, a follow-up e-mail was sent asking the editor to respond even though his or her name did not appear on the postal mail survey packet, and subsequent mailings were directed to that editor by name; however, 36 editors who could not be identified were removed from the sample. Number of editors removed from sample by strata: 27 from less than 25,000 ; 2 from 25,000 to 49,999 , zero from 50,000 to 99,999 , and 7 from more than 100,000 .

77. Donald A. Dillman, Mail and Internet Surveys: The Tailored Design Method (New York: Wiley \& Sons, 2000).

78. Two statements measure the team-based newsrooms construct: Overall, I think the team system of reporting is a more efficient use of newsroom resources than the traditional beat system; Overall, the team system of reporting produces better journalism than the traditional beat system. Construct mean $=2.48$, standard deviation $=.91$, standard error $=$ .06 .

79. Two statements measure the profit construct: I am required to pay too much attention to the bottom line; Our organization's management places more emphasis on non-profits goals (i.e., product quality, organizational efficiency, the latest technology, worker autonomy, and creativity) than profit goals. Construct mean $=2.77$, standard deviation $=.88$, standard error $=.05$.

80. The parameters of the population responses are not known. The standard error of the sample mean indicates the extent to which the sample mean approximates the population mean. The Central Limit Theorem explains that when the sampling distribution of the sample mean is approximately normal (i.e., random sample sizes larger than 30), the probability that the sample mean falls within 2 standard errors of the population mean is close to 95\%. See Alan Agresti and Chris Franklin, Statistics: The Art and Science of Learning from Data (Upper Saddle River, NJ: Pearson/Prentice Hall, 2007), 288-94. The authors note "results of this type are vital to inferential methods that predict how close sample statistics fall to unknown population parameters," 294.

81 . Response rate by strata: $\angle 25 \mathrm{~K} 57$ of $181,31.5 \% ; 25-50 \mathrm{~K}=64$ of 192 , $33.3 \% ; 50-100 \mathrm{~K}=71$ of $200,35.5 \%$; $>100 \mathrm{~K}=71$ of $190,37.4 \%$.

82. Respondent demographics: Gender, 61 (22.3\%) women, 209 (76.3\%) 
men, 4 (1.4\%) did not respond; Ethnicity, 4 African American (1.4\%), 1 Asian American (.3\%), 5 Hispanic/Latino (1.8\%), 239 white (87.2\%), 25 did not respond (9.1\%); Age, range 25 to 70, average 49.9; newspaper experience, range 5 to 52 years, average 26.9 years; time in current position, range 1 month to 36 years, average 6.2 years.

83. Nooteboom, Learning and Innovation in Organizations and Economies, 15-16; Achtenhagen and Raviola, "Organizing Internal Tension," 127-29.

84. Beam, "The Impact of Group Ownership Variables on Organizational Professionalism at Daily Newspapers," 912-13.

85. A single-factor ANOVA found no significant differences in attitudes toward team-based newsrooms by circulation strata (means parenthetically): $<25 \mathrm{~K}$ (2.67), 25-50K (2.37), 50-100K (2.57), >100K (2.31). The data suggest, however, that editors at papers most likely to be working in team-based systems (large papers) have the most negative attitudes toward team-based newsrooms.

86. Neuzil, Hansen, and Ward, "Twin Cities Journalists' Assessment of Topic Teams," 12-14; Gade and Perry, "Changing the Newsroom Culture," 332; Gade, "Newspapers and Organizational Development," $42-43,49$.

87. Several examples of changes that have occurred since the survey was conducted in 2004 include the increased focus and shifting of resources from printed to online newspapers, newspapers' online advertising sharing agreements with Internet companies such as Yahoo and Google, changes in ownership of several leading media companies (e.g., Tribune and Dow Jones), and the dissolution of several publicly owned media companies that were primarily newspaper companies (e.g., Knight-Ridder and Pulitzer). It is, however, worth noting that these changes underscore the importance of the key measures in this study. Integration, whether among firms (several of the above examples) or within organizations (the focus of this study), is a catalyst for innovation, which can impact journalism values and editors' organizational influence.

88. Nooteboom, Learning and Innovation in Organizations and Economics, 35-37; Schein, Organizational Culture and Leadership, 3; Bryman, "Leadership in Organizations," 276-77.

89. Bergquist, The Postmodern Organization, 9. 